\title{
Arbor
}

\section{Estado actual de los estudios sobre teatro breve del Siglo de Oro}

Abraham Madroñal

Arbor CLXXVII, 699-700 (Marzo-Abril 2004), 455-474 pp.

La edición y el estudio del teatro breve del Siglo de Oro es uno de los campos donde las aportaciones han sido más numerosas y relevantes en las últimas décadas. Se ofrece en este trabajo un recorrido desde los años sesenta hasta el presente, que se cierra con una bibliografía selecta de libros, artículos y fuentes principales de carácter electrónico.

Hay en los estudios sobre teatro breve del Siglo de Oro en España unas cuantas fechas emblemáticas entre las que podríamos señalar como término inicial el año 1911, que es cuando don Emilio Cotarelo imprime los dos primeros volúmenes de una serie dedicada a este tipo de teatro, serie que por desgracia se quedaría ahí, dado que diversos avatares hicieron que se suspendiera la publicación de la Nueva Biblioteca de Autores Españoles donde se albergaba. Antes de ese año ya se conocían los entremeses cervantinos, algunos aparecidos en las comedias de Lope o Tirso y los de otros autores como Quiñones. Pero en 1911 se editaba algo así como la «vulgata» de un género, que quedaba estancado en Quiñones de Benavente, cuyas trescientas piezas imprimía Cotarelo como cierre de esa primera etapa de autores. Era su intención continuarla con los entremesistas posteriores a Quiñones, a los que estudia en su magnífica introducción, pero no llegaron a ver la luz los tomos que los contendrían, ni tampoco la bibliografía final, que -sin embargo- se nos conserva manuscrita y ha sido parcialmente editada en la reedición de esta obra pionera 
y seminal con unos necesarios estudios introductorios e índices [SuárezMadroñal, 2000].

Otro año especial en la historia de los estudios y ediciones es sin duda el de 1965, fecha en que dos grandes maestros publican sus obras fundamentales: por un lado Asensio, que había descubierto interesantes piezas manuscritas de Quevedo en bibliotecas portuguesas y las edita junto con un estudio que supone el espaldarazo definitivo para la consideración de al pieza breve. Su Itinerario del entremés [1965, $2^{\mathrm{a}}$ ed. corregida en 1971], por el que todos los estudiosos hemos transitado, abarca desde Lope de Rueda a Quiñones, pero da tan importantes noticias para la consideración de estos géneros que ha servido para cuantos se han acercado a ellos. Por su parte, la gran especialista norteamericana Hannah Bergman publicaba su tesis doctoral este mismo año, centrada en el arte literario de Quiñones, pero en la que precisaba también un buen número de noticias sobre autores, representaciones y otras cosas. Cada uno de ellos reseñó la obra del otro en la misma revista y en páginas consecutivas (Modern Language Notes, 82, 1967). Coincidiendo con ello, Buendía [1965] editaba también una antología del género con que se completaba en la práctica el estudio teórico de los dos maestros citados.

Otro de los años emblemáticos es sin duda 1981, fecha en que tiene lugar un importante congreso para estudiar a Calderón y en la que Rodríguez Cuadros y Tordera se plantean editar su obra menos conocida, justamente sus entremeses, bailes, jácaras, etc, que aparecería poco después. A partir de esa fecha los estudios sobre el teatro breve se han prodigado sobremanera, en parte también debido al importante estudio de Huerta Calvo [1985], que aportaba una nueva antología del género, precedida de un brillante análisis que ha servido también de punto de arranque de buen número de estudiosos posteriores, en buena parte alumnos suyos. El teatro menor había alcanzado su mayoría de edad y a partir de esa última fecha -salvo casos esporádicos- ya no se denominará de esa manera, hasta cierto punto despectiva. Hoy día el plantel de especialistas en esta parcela de nuestra literatura augura un amplio desarrollo del cultivo crítico del género.

El teatro breve ha tenido problemas de nomenclatura, de hecho algunos autores se han dedicado al estudio del término «entremés» [Lázaro, 1965] y otros a defender el cambio de teatro menor a teatro corto [Rodríguez-Tordera, 1983] o breve por las connotaciones peyorativas que llevaba aparejadas [Huerta Calvo, 1985], todavía otros han analizado la definición de Lope del entremés como comedia antigua y se ha estudiado la diferente denominación para aludir a la pieza cómica breve: farsa [Huerta Calvo, 1987], sainete, etc. Para su proteica forma y denominaciones en 
siglos siguientes se puede consultar el trabajo de Huerta Calvo-Peral [2000], que presenta un panorama de la bibliografía del teatro breve de todas las épocas.

En cuando al estudio y edición de autores hay que decir que los del siglo XVI, fundamentales para el establecimiento y primeros pasos de este teatro, están en desventaja en comparación con los autores y las piezas del XVII. Un pionero estudio de conjunto de Jack (1923) sirvió para situar las piezas de todos estos autores en conjunto y para considerar en cierta manera sus orígenes. Rueda, creador para muchos, ha merecido buenas ediciones, entre las que destaca las recientes de Tusón [1981] o Canet [1992], pero no se puede decir lo mismo de Timoneda, cuyo teatro breve tiene que seguir leyéndose en ediciones facsimilares o ya algo anticuadas; Encina cuenta con una magnífica edición y estudio [Pérez Priego, 1991], como también Sánchez de Badajoz [Pérez Priego, 1985], Gil Vicente ha merecido también algún trabajo que lo relaciona con el teatro breve [Tobar, 1983], Horozco tuvo la suerte de encontrar un editor como González Ollé [1979], y poco más se puede señalar en este apartado. Abundan eso sí los estudios sobre estos autores y su aportación a la historia del género, como se puede apreciar en los correspondientes capítulos que se les dedican en la Historia del teatro español [Huerta Calvo, 2003].

Sin duda uno de los más favorecidos desde antiguo ha sido Cervantes, especialmente por la manía de prohijarle buen número de piezas (además de las ocho seguras) que hoy parece descartado que escribiera. Muy bien editado desde fecha bien temprana (Schevill-Bonilla, 1918; Herrero García, 1945), disponemos hoy de buenas ediciones de sus entremeses de Asensio [1970], Canavaggio [1981], Sevilla-Rey [1987], Huerta Calvo [1997] o Sanz Hermida [1998]. Castro [1874] y otros apuntaron que obras como Los romances y otras se le debían y editaron unas cuantas, algunas que no se sostienen como obra suya precisamente por el anacronismo que supone adjudicarle Doña Justina y Calahorra, por ejemplo. Alonso [1936, reed. 1987] y otros han editado Los habladores o La cárcel de Sevilla y otras piezas alguna vez atribuidas. En lo que se refiere a los estudios, contamos con algunos magníficos de Asensio [1973] o Canavaggio [1977] y, más recientemente, Zimic [1992], Reed [1993, 1994] o Chevalier [1999], entre una muchedumbre de análisis y consideraciones particulares de los temas que trató en estas obritas, comparaciones con otras no entremesiles, etc., como se puede apreciar en el reciente Anuario bibliográfico cervantino [2001]. También se ha analizado el Quijote en su relación con el teatro breve, por cuanto algunas de sus episodios tienen claro carácter entremesil. 
Otro gran nombre en la evolución de estos géneros es Quevedo, cuyos entremeses tienen amplia tradición editorial, por cuanto se editaron desde antiguo (es verdad que en reducido número en la ed. BAE, 1877 o en Premáticas, 1929) y, posteriormente por Astrana de forma irregular, añadiendo algunos títulos más que dudosos [1943], que reprodujo Buendía. Modernamente se ha visto matizado y mejor editado por críticos posteriores como Crosby [1968] y, especialmente, Blecua [1981] y hoy Arellano [1984] y con García Valdés [1997, 2001] y otros. Mancini [1955] le dedicó un buen análisis general y Asensio se preocupó de allegar un número no desdeñable de estas piezas [1965] y de estudiar tipos suyos como Diego Moreno [1959]. Más recientemente se han dedicado análisis generales [Hernández Araico, 2004] y también otros particulares, por ejemplo al Marión [Linares, 2003] y su relación con el carnaval [Alonso Hernández, 1999] o el lenguaje de sus bailes [Snell, 1994].

El tercer gran nombre del entremés es sin duda Quiñones de Benavente, cuyo punto de arranque crítico hay que situarlo en 1872, fecha en que don Cayetano Rosell, «devoto del autor», recupera sus entremeses editando la Jocoseria en un tomo y seleccionando en otro los que más interés le suscitaban. Cotarelo utilizó esta edición para la suya (Colección, 1911), pero añadiendo todas las piezas que le vinieron a la mano sin demasiado cuidado editorial. Con mucho más rigor ha sido estudiado por Turner (1939) y, sobre todo, por Bergman [1965] y Asensio [1965 y 1971], hoy se han aportado nuevos datos biográficos y piezas desconocidas [Madroñal, 1996] y, por fin la edición crítica de la Jocoseria [2001].

Otros nombres importantes son los de Calderón y. Moreto, el primero de los cuales ha merecido buenos estudios [Granja, 1981, 1981b, 1984, 1985; Meregalli, 1989; Rodríguez Cuadros, 2000, 2000b, 2001 y Rodríguez Cuadros-Tordera, 1983] y dos buenas ediciones [Rodríguez Cuadros-Tordera, 1982; Lobato, 1989], que se completan con ediciones y atribuciones de piezas concretas [Rull, 1980; Escudero-Pinillos, 1996]. Moreto, estudiado por Balbín [1942, 1954], Castañeda [1981] o SánchezImízcoz [1994], por fin ha conocido la tan necesaria edición de su obra cómica breve completa [Lobato, 2003].

Grandes autores como Lope o Tirso, de los que no se sabe a ciencia cierta si compusieron entremeses han tenido una serie de estudios que así lo defienden [Rodríguez-Cuadros, 1991; Escudero, 2001] y para el segundo [Bonilla y San Martín, 1909; Apellániz, 1994, pero véase en Nuevos entremeses de Quiñones, 1996]. No hay seguridad, sin embargo, en que se dedicaran a la composición de estas obritas. Los entremeses publicados en sus partes de comedias se están viendo beneficiados por la 
Estado actual de los estudios sobre teatro breve...

edición de obras completas de los dramaturgos, es el caso de los que aparecieron en las partes de Lope o de Tirso, concretamente del primero, magníficamente editados críticamente y estudiados [Pontón-Sánchez Aguilar, 1997], dentro del grupo PROLOPE. Atribuciones más pintorescas, como la única pieza adjudicada a Góngora, han sido rechazadas con toda razón [Jammes, 1978].

Otros autores han merecido reciente atención como Avellaneda [tesis de Gema Cienfuegos, 2004], Castillo Solórzano [Domínguez de Paz, 1987], Lanini [tesis de Hae Zoon Won, 1997], Navarrete y Ribera [Gallo, 2001], Quirós [García Valdés, 1984], Solís, del cual se hizo una edición que no es definitiva [Sánchez Regueria, 1986] y otras parciales [Serralta, 1987], Suárez Deza [Borrego, 2000, 2002], Vélez padre [Urzáiz, 2002], Zamora, [tesis de Rafael Martín, 2004]. Hemos recuperado piezas y nombres como Ordóñez de Ceballos [Valladares, 1998], Urtarrox [Gates, 1971] o Leiva [Cuevas-Garcés, 1994]. Un terreno algo desatendido es el de los entremeses de autores bilingües, que se empiezan a recuperar ahora, es el caso de los portugueses, como Cordeiro o Coelho Rebello [Deprettis, 1999] y, más recientemente, del valenciano Morlá [Madroñal, en prensa]. En lo que toca al entremés de América destacan los nombres de González de Eslava, editado por García Icazbalceta, que ha conocido nuevas y recientes ediciones [Tovar, 1988] y estudios [Frenk, 1989; Solórzano, 1993]. También el bautizado como primer entremés americano, la Láurea crítica de Fernández Valenzuela [Arrom-Rivas Sacconi, 1960]; la obra de Lorenzo de las Llamosas [Zugasti, 1999], entremeses mejicanos del XVIII [López Mena, 1994] o los autores más conocidos como Valle y Caviedes, bien editado por García-Abrines [1993] y, por supuesto, Sor Juana Inés de la Cruz, editada por Méndez Plancarte (1951) y, más recientemente, por Sabat de Rivers [1983], y muy estudiada como una de las representantes máximas del teatro barroco americano [Arango, 2000].

El camino de las ediciones nos lleva al recuento de algunas que han aparecido en facsímil en los últimos años, tal es el caso de la Jocoseria, en una reproducción lastimosa por cuanto utiliza para completar un ejemplar falto de la primera edición (1645) otro de una edición posterior, pero merece la pena destacarse la reproducción primorosa de Navidad y Corpus Christi [1983]. Otras se han hecho con reproducción cuidada, aunque no facsimilar, como es el caso de las tempranas Migajas del ingenio (s.a., ed. Cotarelo, 1908) o Entremeses y flor de sainetes (1657, ed. Menéndez Pelayo, 1903) o de las más recientes Verdores del Parnaso (1668), o del Vergel de entremeses (1671). Pero sigue faltando la reproducción fiel, cuidada y anotada, de estas antologías de la época que tu- 
vieron especial éxito entre la década de 1640 y finales de siglo y que siguieron cosechándolo en la centuria siguiente. Es verdad que las antologías modernas han venido a llenar un hueco de textos: Bergman [1970, $2^{\mathrm{a}}$ ed., 1984], García Valdés [1985, reed. en 2003], Huerta publicaba la suya pionera, dedicada a los siglos XVI y XVII [1985] y más recientemente otra dedicada al último de los siglos [1999]; hoy contamos también con la de Vellón [2004] y con la de Doménech, dedica al teatro breve de mujeres [1996]. Igualmente existen las traducidas al francés (Rouanet, 1897) e italiano (Vian, 1959) y otras dedicadas a un solo autor, como Quiñones [Bergman, 1968; Blecua, 1971; Andrès, 1991], y una muy necesaria dedicada al siglo XVIII [Doménech, 1997]. Gracias a esas ediciones y estudios particulares el teatro breve ha entrado por mérito propio por la puerta grande de estudios panorámicos como la citada Historia del teatro español [Huerta Calvo, 2003] y volúmenes colectivos como Géneros menores, Teatro menor, Teatro breve, Teatro y carnaval o El gran mundo del teatro breve; también ha merecido estudios generales como el de Huerta [2001] y otros.

El estudio del teatro breve también ha alcanzado a algunos de sus personajes, como es el caso del más famoso de todos Juan Rana, cuya primera biografía publicó Cotarelo [Colección, 1911], luego ampliada por Bergman [1965] y sobre quien se han aportado datos muy interesantes que tocan a su inclinación sexual y son necesarios para entender las piezas en que aparece [Serralta, 1990]. Más recientemente sigue cosechando buen número de referencias, tanto en lo biográfico [Granja, 2001; tesis de Francisco Sáez Raposo, 2003 que aporta nuevos doumentos] como en la exhumación de nuevas piezas [Lobato, 1998, 1999, 2002; Sáez Raposo, 2003] y junto con él actrices como Quiteria [Kennedy, 1972-73]. También se ha prestado atención a ciertos tipos como los indianos [Ripodas, 1991], los negros [Fra Molinero, 1995], los marginados [Castro de Moux, 1997], los extranjeros o el caso de tipos concretos como Diego Moreno [Asensio, 1959], el Niño de la Rollona [Faliu-Lacourt, 1991] o Juan Francés [Madroñal, 1996].

Algunas piezas han merecido atención particular por su propia singularidad o su importancia en el nacimiento y evolución de estos géneros, es el caso de obra como el entremés de los romances [Millé, 1930; Pérez Lasheras, 1988; Stagg, 2002], el del Conde Alarcos [García Lorenzo, 1974; Castro de Moux, 1996], el de los invencibles hechos don Quijote [García Lorenzo, 1978; Vilches, 1985], el de Pascual Rábano [Senabre, 1979], el de Píramo y Tisbe [Senabre, 1981], el de los negros de Simón Aguado [Castro de Moux, 1993], el del mico [Soons, 1996], el del alcaide de Mairena, pieza del XVII rehecha y censurada en el XVIII 
[Madroñal, 1998b], el de Melisendra [Cuenca Muñoz, 1999; Gómez, 2001] y otros.

También la atención a los diferentes subgéneros ha crecido en los últimos tiempos, así se han dedicado números monográficos del teatro breve; se han estudiado las loas, por ejemplo de Bances Candamo [Arellano et al., 1994] o de Lope y otros de su tiempo [Antonucci-Arata, 1995], también las de Salazar y Torres [Farré Vidal, 2003] y otros; la jácara [Rodríguez Cuadros, 1983b; Alonso Hernández, 1989]; la mojiganga ha merecido un libro importante [Buezo, 1993] y algunos estudios particulares [Buezo, 2000; Lobato, 2000; Zugasti, 2002]; a los bailes dedicó Merino Quijano una tesis [1981] y hoy han recibido nuevos estudios [Gutiérrez de la Concepción, 1997], y la folla también ha sido objeto de estudio [Estepa, 1994], por más que la opinión bien fundamentada de Huerta la descarte como tal género [2001: 80]. Y sobre todo el entremés, ya sea en general [Martínez López, 1997] o de determinados tipos, como el jesuítico [Madroñal et al., 1996], el de los escolapios [Figueras Martí, 1981], etc.; también sus relaciones con el cuento, la novela [Fernández Nieto, 1983], el refranero [Recoules, 1976], o el romancero [Recoules, 1975; Bergman, 1961, dedicado a Quiñones]. A la reflexión teórica sobre el entremés dedicó una buena antología Newels [1974] y un trabajo monográfico Huerta Calvo [1988].

Algunos de los temas del teatro breve, que también convienen a otras formas de teatro se han analizado particularmente, como su relación con el carnaval [Huerta, 1988; Estepa, 1994], el tópico del mundo al revés, la tierra de Jauja [Madroñal, 1998c], el erotismo o la comicidad [Profeti, 1992; Granja, 1994; Huerta Calvo, 1995], el juego [Étienne, 1990], la burla [Madroñal, 2001], la lengua del entremés [Senabre, 1988; Martín Fernández, 1999, 2000, 2001, aplicado a Quiñones], el vestuario [Rodríguez Cuadros, 2000], la moralidad [Madroñal, 1999b], la ideología [Vitse, 1988], la parodia [Crespo Matellán, 1979; Buezo, 2002, en Calderón], la sátira [Chul, 1999, dedicado a Cervantes], los aspectos costumbristas [García SantoTomás, 2004], el tema del matrimonio [Chauchadis, 1980] o el de la mujer [Buezo, 1998], las ventas [Martínez, 2002], la relación con la comedia burlesca [García Lorenzo, 1982; Madroñal, 1998] o la fiesta [Díez Borque, 1984; Huerta, 1986], con los personajes del sainete [Martínez, 1997], la métrica [Lobato, 1990, 1991] o la música [Antón Priasco, 2003].

Afortunadamente ha seguido la catalogación de manuscritos e impresos del teatro breve que llevara a cabo Recoules en una tesis que merecería traducirse, Les intermèdes des collections imprimées (Lille, 1973); también la de bibliotecas importantes en este tipo de piezas como la Menéndez Pelayo o el Instituto del Teatro de Barcelona; se ha elaborado 
un nuevo catálogo de autores del XVII [Urzáiz, 2002] y disponemos del de los entremeses del XVIII [Fernández Gómez, 1993], los de la Academia Española [Madroñal, 1995], los impresos en Sevilla [Vega GarcíaLuengos, 1991] o los que poseía el infante Antonio Pascual de Borbón [Rodríguez, 2000]. Una magnífica bibliografía general sobre el teatro breve ha venido a recoger las aportaciones parciales de diferentes críticos [Granja-Lobato, 1999] ${ }^{1}$. Conocemos gracias a todo ello y al desvelo de los investigadores un buen conjunto de nuevas piezas, que han sido editadas modernamente, como el de Entre bobos anda el juego [García Valdés, 1984], el del pícaro pobre [González Cañal, 1993] o el de Pantalón Mondapozos de finales del XVI [Lobato, 1998].

Se han estudiado las raíces del teatro breve: su vinculación con el corpus [Granja, 1988], planteando nuevos orígenes a los admitidos tradicionalmente [Serrà, 1987] y su relación con el carnaval, desde la óptica de los estudios bajtinianos. De la misma forma la proyección del teatro breve en otros tiempos, el influjo en teatro francés [Losada, 1999], su difusión en el XVIII [Palacios, 1983], pero más concretamente en autores como González del Castillo, Cruz; la relación con la farsa [Huerta Calvo, 1987] y la consideración del entremés en otras lenguas [Serrá, 1987, para el catalán; Cortijo Ocaña, 2000 para el gallego-portugués].

$\mathrm{Y}$ como el teatro no es solo texto y particularmente el teatro breve es representación hay que destacar los análisis que sobre las escenificaciones de piezas breves se han llevado a cabo y aspectos como el estudio de la escenografía [García Lorenzo, 1990] o la técnica actoral [Rodríguez Cuadros, 1998].

Por supuesto, se siguen echando de menos estudios y ediciones importantes, como la que se debe a Cáncer [en curso] o a Torres Villarroel, bien estudiado por Sala Valldaura [1999] y, especialmente, se ha de seguir catalogando bibliotecas públicas y principalmente privadas, que arrojarán mucha luz y buen número de piezas desconocidas. Hace falta un catálogo de entremeses, loas, bailes, jácaras y mojigangas del Siglo de Oro, a pesar de que conocemos un buen número de catálogos manuscritos que nunca vieron la luz y a pesar del publicado por La Barrera en 1860, muy mejorado por Urzáiz [2002].

Las páginas de internet y los recursos electrónicos dedicados al teatro van creciendo, así disponemos de importantes bancos de textos como el de TESO, COMEDIA o la Biblioteca Virtual Miguel de Cervantes; también corpus textuales que los incorporan en buena medida como el COR$\mathrm{DE}$, que permiten la búsqueda dentro de estas piezas y su uso para la enseñanza e investigación. 


\section{Estado actual de los estudios sobre teatro breve...}

\section{Notas}

1 Por esa misma razón en este trabajo doy preferencia a la bibliografía aparecida después del año de publicación de este libro, aunque no puedo dejar de señalar algunos trabajos anteriores por su importancia.

\section{Bibliografía}

\section{A) Ediciones}

Antología del entremés barroco, ed. de Celsa Carmen García Valdés, Barcelona, Plaza \& Janés, 1985.

Antología del entremés barroco, ed. de Celsa Carmen García Valdés, Madrid, LibertariasProdhufi, 2003.

Antología del entremés (desde Lope de Rueda hasta Antonio de Zamora), ed. Felicidad Buendía, Madrid, Aguilar, 1965.

Antología del teatro breve español del siglo XVII, ed. Javier Huerta Calvo, Madrid, Biblioteca Nueva, 1999.

Antología del teatro breve español del siglo XVIII, ed. Fernando Doménech, Madrid, Biblioteca Nueva, 1997.

Antología de obras cortas dramáticas del Barroco, ed. J. Vellón Lahoz, Valencia, Brosquil, 2004.

CALdERÓN DE LA BARCA, PEDRO: Entremeses, jácaras y mojigangas, ed. Evangelina Rodríguez y Antonio Tordera, Madrid, Castalia, 1982.

- Teatro cómico breve, ed. Ma Luisa Lobato, Kassel, Reichenberger, 1989.

Cervantes, Miguel De: Entremeses, ed. Eugenio Asensio, Madrid, Castalia, 1970.

- Entremeses, ed. Jean Canavaggio, Madrid, Taurus, 1981.

- Entremeses, ed. Jacobo Sanz Hermida, Madrid, Espasa-Calpe, 1998.

- Teatro completo, ed. Florencio Sevilla y Antonio Rey Hazas, Barcelona, Planeta, 1987.

Colección de entremeses, loas, bailes, jácaras y mojigangas, ed. Emilio Cotarelo, Madrid, Bailli-Baillière. Ed. facsímil con estudio preliminar e índices por José Luis Suárez y Abraham Madroñal, Granada, Universidad de Granada, 2000.

EnCINA, JUAN DEL: Teatro completo, ed. Miguel Ángel Pérez Priego, Madrid, Cátedra, 1991.

Horozco, Sebastián DE: Representaciones, ed. de F. González Ollé, Madrid, Castalia, 1979.

Intermèdes espagnols du XVIIe siècle traduits, avec un préface et des notes par Léo Rouanet. Paris, Impr. Noizette et Cie, 1897.

NAVARRETE Y RiBERA, FrANCISCO: Flor de sainetes, introduzione, testo critico e note di Antonella Gallo, Firenze, Alinea Editrice, 2001.

Moreto Agustín: Loas, entremeses y bailes, ed. M. ${ }^{a}$ Luisa Lobato, Kassel, Reichenberger, 2003, 2 vols.

Navidad y Corpus Christi festejados por los mejores ingenios de España, Hildesheim-Zürich-New Cork, Georg Olms Verlag, 1983.

Quevedo, Francisco DE: Entremeses, ed. José Manuel Blecua, Obra poética, IV, Madrid, Castalia, 1981. 
- Obras completas, verso, ed. Luis Astrana Marín, Madrid, Aguilar, 1943.

- Premáticas, desenfados y entremeses, Madrid, Aguilar, 1929.

QuiÑones DE BENAVEnTE, Luis: Entremeses, ed. Hannah E. Bergman, Salamanca, Anaya, 1968.

- Entremeses, ed. José Manuel Blecua, Zaragoza, Ebro, 1971.

- Entremeses, ed. Christian Andrès, Madrid, Cátedra, 1991.

- Jocoseria, ed. Ignacio Arellano, Juan Manuel Escudero, Abraham Madroñal, Pamplona-Madrid, Iberoamericana-Vervuert, 2001.

- Nuevos entremeses atribuidos a Luis Quiñones de Benavente, ed. Abraham Madroñal Durán, Kassel, Reichenberger, 1996.

QUIRÓs, FrANCISCO BERNARDO: Obras. Aventuras de don Fruela, ed. Celsa Carmen García Valdés, Madrid, Instituto de Estudios Madrileños, 1984.

Ramillete de entremeses y bailes nuevamente recogidos de los antiguos poetas de España, siglo XVII, ed. Hannah Bergman, Madrid, Castalia, 1984, $2^{\text {a }}$ ed.

RuedA, Lope DE: Pasos, ed. F. González Ollé y V. Tusón, Madrid, Cátedra, 1981.

- ed. J. L. Canet, Madrid, Castalia, 1992.

SÁnchez de Badajoz, Diego: Farsas, ed. Miguel Ángel Pérez Priego, Madrid, Cátedra, 1985

Solís, AnTONIO DE: Obra dramática menor, ed. Manuela Sánchez Regueira, Madrid, CSIC, 1986.

SOR JUANA InÉS DE LA CRUZ: Inundación castálida, ed. Georgina Sabat de Rivers, Madrid, Castalia, 1983.

SuÁREZ DE DeZA, ViCEnTE: Teatro breve, ed. Esther Borrego, Kassel, Reichenberger, 2000, 2 vols.

Teatro breve de los siglos XVI y XVII, ed. Javier Huerta Calvo, Madrid, Taurus, 1985.

Teatro breve de mujeres (siglos XVII-XX), ed. Fernando Doménech Rico, Madrid, Asociación de Directores de Escena de España, 1996.

Valle Caviedes, Juan: Obra poética, ed. Luis García-Abrines Calvo, Jaén, Diputación Provincial, 1993, 2 vols.

VEGA, LoPE DE [?]: Entremeses. Parte I de Comedias, Ed. G. Pontón y A. Sánchez Aguilar, Lledia, Milenio, 1997, vol. 3.

VÉLEZ DE GuevarA, LuIs: Teatro breve, ed. Héctor Urzáiz, Madrid, Iberoamericana-Vervuert, 2002.

Verdores del Parnaso, ed. R. Benítez Claros, Madrid, CSIC, 1969.

Vergel de entremeses, ed. J. Fernández Cañedo, Madrid, CSIC, 1970.

\section{B) Estudios}

AlONSO, DÁMASO (1936): El hospital de los podridos y otros entremeses alguna vez atribuidos a Cervantes, Madrid, Signo. [Reed. Madrid, Mayo de Oro, 1987.

ALONSO HERNÁNDEZ, JOSÉ LUIS (1989): “Los lenguajes de la jácara en su metamorfosis», $E l$ teatro español a fines del XVII. Diálogos hispánicos de Amsterdam, 8, II, pp. 603-622.

- (1999): "Ausencias y presencias del carnaval en los entremeses de Quevedo", en Teatro y carnaval, pp. 101-129.

Álvarez BARrientos, J. y A. Cea GutiérRez (coords.) (1987): Actas de las jornadas sobre teatro popular en España, Madrid, CSIC.

ANTÓN PRIASCO, SUSANA (2003): «La reutilización de música preexistente en el tratro breve del siglo XVII. Repertorio y procedimientos", en Edad de Oro, 22, pp. 265-281. 
ANTONUCCI, FAUSTA (1994-1996): “Teatro breve e feste di palazzo: le loas' cortigiane di Agustín de Salazar y Torres", en Atti del Seminario su 'La scrittura dell'effimero', Studi Ispanici, p. 99-110.

- y ARATA, Stefano (1995): : La enjambre mala soy yo, el dulce panal mi obra, Valencia, UNED-Universidad de Sevilla-Universitat de València.

APEllÁNIZ, Ma Dolores (ed.) (1994): Entremés de Los ladrones aporreados de Tirso de Molina, edición facsímil del manuscrito inédito del A.H.N, Madrid, Revista Estudios.

Arango, Manuel Antonio (2000): Contribución al estudio de la obra dramática de Sor Juana Inés de la Cruz, New York, Peter Lang.

ARELlano, IgNACio (1984): “Anotación filológica de textos barrocos: el Entremés de la vieja Muñatones, de Quevedo", en Notas y Estudios Filológicos, [1], pp. 87-117.

ARELlano, IGNACIO y CELSA C. GARCía VAldéS (1997): «El entremés El marido pantasma, de Quevedo", en Perinola, 1, pp. 41-70.

- (2001): : “Entremés de la ropavejera, de Quevedo», en Perinola, 5, pp. 25-38.

ARellano, Ignacio y Kurt Spang y M. CARMEn Pinillos (1994): Apunte sobre la loa sacramental y cortesana: Loas completas de Bances Candamo, Kassel, Reichenberger.

ARROM, José JUAN y José MANUEl RIVAS SACCONI (1960): «La Laurea crítica de Fernando Fernández Valenzuela, primera obra teatral colombiana", Bogotá, Instituto Caro y Cuervo, 1960.

Asensio, Eugenio (1959): «Hallazgo de Diego Moreno, entremés de Quevedo y vida de un tipo literario", $H R, 27$, pp. 397-412.

- (1971): Itinerario del entremés, Madrid, Gredos, $2^{\mathrm{a}}$ ed. revisada.

- (1973): “Entremeses”, en Suma Cervantina, ed. J. B. Avalle-Arce y E. C. Riley, London, Tamesis, pp. 171-197.

BACHILler MANTUANo (1909): Entremeses del siglo XVII atribuidos al maestro Tirso de Molina, Madrid, Biblioteca "Ateneo".

BADUI DE ZOGBI, MARÍA BANURA (1997): «El valiente Escarramán. De la jácara al entremés", En Cervantes, Góngora y Quevedo. [Actas del II Simposio Nacional Letras del Siglo de Oro español], Mendoza, Universidad Nacional de Cuyo, p. 115-126.

BERGMAN, HANNAH E. (1961): "El romancero en Quiñones de Benavente», en NRFH, 15, pp. 229-246.

- (1965): Luis Quiñones de Benavente y sus entremeses, Madrid, Castalia.

- (1966): «Juan Rana se retrata», en Homenaje a Antonio Rodríguez Moñino, I, Madrid, Castalia, pp. 65-73.

- (1972): "Algunos entremeses desconocidos de Luis Quiñones de Benavente», en Homenaje a Casalduero, Madrid, Gredos, pp. 85-94.

- (1975): "Los refranes del viejo celoso y obras afines", NRFH, 24, pp. 376-397.

Bolaños Donoso, Piedad y Mercedes de los Reyes PeÑa (1997): «Teatro español en Lisboa durante la temporada de 1724-25: la fiesta de Las nuevas armas de amor", en Música y literatura en la Península Ibérica: 1600-1750, ed. M. A. Virgili Blanquet, G. Vega García-Luengos y C. Caballero Fernández-Rufete, Valladolid, V Centenario Tratado de Tordesillas, pp. 13-30.

Bonilla Y SAN MARTÍN=BACHILler MANTUANO.

BorREgo, ESTHER (2002): Un poeta cómico en la corte. Vida y obra de Vicente Suárez Deza, Kassel, Reichenberger.

Buezo Canalejo, Catalina (1990): «El sacristán fariseo. Edición de un entremés inédito y apuntes sobre la figura del fariseo", en Criticón, 50, pp. 93-112.

- (1993): La mojiganga dramática. De la fiesta al teatro, Kassel, Reichenberger. 
- (1998): «Mujer y desgobierno en el teatro breve del siglo XVII: el legado de Juan Rana en Teresa de Robles, alcalde gracioso y 'autora' de comedias”, en Teatro y poder, pp. 107-119.

- (2000): "Mecanismos de género: algunas mojigangas anónimas de la escuela de Calderón", en Calderón, protagonista eminente del teatro europeo. Ed. Kurt y Teo Reichenberger. I, Kassel, Reichenberger, pp. 397-414.

- (2002): “Conciencia de género y autoparodia en el teatro breve calderoniano: La negra, una mojiganga de posible atribución a don Pedro Calderón de la Barca", en Calderón entre burlas y veras. Ed. F. Domínguez Matito y J. Bravo Vega, Logroño, Universidad de La Rioja, pp. 115-138.

- (2002): «Venta y ventero en una pieza, de Antonio de Escamilla, o el cuerpo como lugar escénico", en Homenaje a Frédéric Serralta. Eds. Françoise Cazal, Christophe González y Marc Vitse, Madrid, Universidad de Navarra-Iberoamicana-Vervuert, pp. 117-136.

CANAVAGgio, JEAN (1997): Cervantes dramaturgue: un théâtre à naître, Paris, PUF.

CANET, JOsÉ LUIS (1991): "Algunas puntualizaciones sobre los orígenes del teatro popular en España", Comedias y comediantes, Valencia, Universitat de València, pp. 88-99.

Caro BAROJA, Julio (1979): El carnaval (Análisis histórico cultural), Madrid, Taurus, $2^{\mathrm{a}}$ ed.

Castañeda, James A. (1981): «Una veta inexplorada de la brava mina de Moreto: su teatro menor", en Studies in honor of Everett W. Hesse, Nebraska-Lincoln, Society of Spanish and Spanish-American Studies, pp. 49-61.

CASTRO, AdOLFO DE (ed.) (1874): Varias obras inéditas sacadas de códices de la Biblioteca Colombina, de Miguel de Cervantes, Madrid, Aribau.

Castro de Moux, MARÍA E. (1993): «Tipos de discurso teatral en el Entremés de los negros de Simón Aguado", en BCom, 45, pp. 53-66.

- (1996): "Parodia literaria y caricatura de la corte: Nobleza y realeza en el Entremés del conde Alarcos", en Mira de Amescua en candelero, ed. A. de la Granja y J. A. Martínez Berbel, Granada, Universidad de Granada, pp. 57-75.

- (1997): La casa de los linajes. Oficios y gentes marginados en el entremés barroco español, Nueva Orleans, University of the South.

Chauchadis, C. (1980): "Risa y honra conyugal en losa entremeses", en Risa y sociedad en el teatro español del Siglo de Oro, Paris, CNRS, pp. 165-183.

Chevalier, MAXime (1988): “Caricatura quevediana y figuras del entremés», Géneros menores, pp. 149-161.

- (1999): "Sobre el entremés cervantino", en Cuento tradicional, cultura, literatura (siglos XVI-XVII), Salamanca, Universidad de Salamanca, pp. 99-103.

CHUL, PARK (1999): “La sátira en los entremeses de Cervantes», en Estudios Hispánicos, 15, pp. 1-23.

Cotarelo y Valledor, Armando (1915): El teatro de Cervantes, Madrid, Archivos.

CRESPO MATELlÁN, SALVAdOR (1979): La parodia dramática en la literatura española, Salamanca, Universidad.

CoRtiJo OCAÑA, ANTONio (2000): La colección Fernán Núñez de la Bancroft Library. Catálogo y estudio, London, Quenn Mary \& Westfield College.

Coulon, Mireille (1983): «El sainete de costumbres teatrales en la época de don Ramón de la Cruz", Teatro menor, pp. 235-249.

Crosby, James O. (1967): En torno a la poesía de Quevedo, Madrid, Castalia.

Cuenca MuÑoz, PIlar (1999): “Estudio paleográfico de algunos autógrafos teatrales de Lope de Vega y edición del entremés de Melisendra (Res. 88)", CILH, 24, pp. 149-193. 


\section{Estado actual de los estudios sobre teatro breve...}

Cuevas, Cristóbal y Elena Garcés (1994): Una comedia y dos entremeses inéditos, de Francisco de Leiva, Málaga, Real Academia de Bellas Artes de San Telmo.

Davies, Gareth A. (1971): A Poet at Court: Antonio Hurtado de Mendoza (1586-1644), Oxford, The Dolphin Book.

DEPRETIS, GIANCARLO (1999): L'entremés como genere letterario, Turín, Edizioni dell'Orso.

Diago, MANuel V. (1990): «Lope de Rueda y los orígenes del teatro profesional», en Criticón, 50, pp. 41-65.

- (1994): «El simple, un precedente de la figura del gracioso», en El gracioso en el teatro español del Siglo de Oro, Actas del VI Coloquio del GESTE, en Criticón, 60, pp. 19-26.

DíEZ BoRQUE, José MARÍA (1984): Una fiesta sacramental barroco, Madrid, Taurus.

DOMíNGUEZ DE PAZ, ELISA (1987): “Construcción y sentido del teatro breve de Alonso del Castillo Solórzano" BRAE, 67, pp. 251-270.

ESCUDERO BAZTÁN, JUAN MANUEL (2001): «El teatro breve de Lope de Vega», Ínsula, 658, pp. 15-16.

- y M. CaRmen Pinillos (1995): “El entremés de La tía de F. Monteser (edición)», en RILCE, 11, pp. $139-168$

- (1996): «El entremés de La tía, atribuido a Calderón», en RILCE, 12, pp. 227-248.

ESTEPA, LUIS (1994): Teatro breve y de carnaval en el Madrid de los siglos XVI y XVII, Madrid, Comunidad de Madrid.

ÉtIENVRE, JEAN-PIERE (1990): Márgenes literarios del juego, Madrid, Tamesis.

FAliU-LacourT, Christiane (1991): «El Niño de la Rollona», en Criticón, 51, pp. 51-56.

FARRÉ VIDAL, JUDITH (2003): Dramaturgia y espectáculo del elogio. Loas completas de Agustín de Salazar y Torres, Kassel, Reichenberger, 2 vols.

FERNÁNDEZ GómeZ, JUAN F. (1993): Catálogo de entremeses y sainetes del siglo XVIII, Oviedo, Instituto Feijoo del siglo XVIII.

FERNÁNDEZ NIETO, MANUEL (1983): «El entremés como capítulo de novela: Castillo Solórzano", Teatro menor, pp. 189-198.

Figueras Martí, Miguel Á. (1981): Teatro escolar zaragozano, las Escuelas Pías en el siglo XVIII, Zaragoza, Institución Fernando el Católico.

Fra Molinero, Baltasar (1995): La imagen de los negros en el teatro del Siglo del Oro. Madrid, Siglo XXI

FRENK, MARGIT (1989): “Introducción» a Fernán González de Eslava, Villancicos, romances, ensaladas y otras canciones devotas, México, El Colegio de México.

García Lorenzo, LuCiano (1974): «Entremés del Conde Alarcos», Prohemio, 5, pp. 119135.

- (1978): "Entremés famoso de los invencibles hechos de don Quijote de la Mancha, de don Francisco de Ávila», $A C$, 17, pp. 259-273.

- (1982): "A propósito de El hermano de su hermana, de Bernardo de Quirós y la comedia burlesca del siglo XVII", Rlit, 44, pp. 5-24.

- (1990): "La escenografía de los géneros dramáticos menores", Aurora Egido (ed.), La escenografía del teatro barroco, Universidad de Salamanca-Universidad internacional Menéndez Pelayo, pp. 127-139.

GARCía SANTO-TOMÁS, ENRIQUe (2004): Espacio urbano y creación literaria en el Madrid de Felipe IV, Madrid, Vervuert -Iberoamericana.

García VAldés, Celsa C. (1983): "El sordo y Don Guindo, dos entremeses de «figura» de Francisco Bernardo de Quirós», en Segismundo, 17, pp. 241-269. 
- (1984): «Un entremés inédito de Francisco Bernardo de Quirós: Entre bobos anda el juego", en Segismundo, XVIII, pp. 291-308.

Gates, Eunice J: (1971): “An unpublished "entremés" by Andrés de Uztarroz», en Homenaje al profesor William L. Fichter, Madrid, Catalia, pp. 229-239.

Géneros menores = Los géneros menores en el teatro español del Siglo de Oro. Ed. Luciano García Lorenzo, Madrid, Ministerio de Cultura, 1988.

GÓMEZ, JESÚS (2001), «El entremés de Melisendra atribuido a Lope de Vega y los orígenes de la "comedia burlesca", BRAE, 81, pp. 205-221.

GÓMEZ MonTERo, JAVIER (1998): "Las metamorfosis del viejo celoso y la heurística de la representación en Cervantes, en Teatro español del Siglo de Oro: Teoría y práctica, ed. Christoph Strosetzki, Madrid, Iberoamericana, pp. 131-158.

GONZÁLEZ CAÑAL, RAFAEL (1993): “Un entremés olvidado de principios del siglo XVII: $E l$ testamento del pícaro pobre de Damón de Henares", en BCom, 45, pp. 277-309.

Gran mundo $=E l$ gran mundo del teatro breve, coord. Por J. Huerta Calvo. Ínsula, $\mathrm{n}^{\circ} 639$ 640 (2000).

GRANJA, AGUSTÍN DE LA (1981): Entremeses y mojigangas de Calderón para sus autos sacramentales, Granada, Universidad de Granada.

- (1981): "Calderón de la Barca y el Entremés de la Melancólica», en Ascua de veras. Estudios sobre la obra de Calderón, Granada, Universidad de Granada, pp. 57-85.

- (1984): “Cinco obras cortas atribuibles a Calderón», en Bhi, 86, pp. 355-378.

- (1985): «Los entremeses de la premática, de Calderón (Notas y addenda a una edición crítica)", en Estudios románicos dedicados al prof. Andrés Soria Ortega, II, ed. J. Montoya Martínez y J. Paredes Núñez. Granada: Universidad de Granada, pp. 257274.

- (1988): «El entremés y la fiesta del Corpus», Criticón, 42, pp. 139-153.

- (1994): “Una loa para La cena de Baltasar y probable estreno (Madrid, 1635) del auto calderoniano", Hacia Calderón. Décimo coloquio anglogermano, Stuttgart, Franz Steiner Verlag, pp. 147-163.

- (1994): “El entremés: la larga risa de un teatro breve», Del horror a la risa, Kassel, Reichenberger, p. 161-189.

- (2001): "Los dos testamentos de Cosme Pérez, alias Juan Rana», en Actas del V Congreso de la Asociación Internacional Siglo de Oro, Madrid, Iberoamericana-Vervuert, pp. 652-662.

- y MARÍa LUISA LoBATo (1999): Bibliografia descriptiva del teatro breve español (Siglos $X V$-XX), Madrid, Universidad de Navarra-Iberoamericana-Vervuert.

GutiérRez de la Concepción, María Nieves y Beatriz Montes (1997): «El entremés cantado o baile: música, danza y literatura en el teatro menor del Siglo de Oro". En Música y literatura en la península ibérica: 1600-1750. Eds. M. A. Virgili Blanquet, G. Vega García-Luengos y C. Caballero Fernández-Rufete, Valladolid, Junta de Castilla y León, Universidad de Valladolid, Central-Hispano, p. 377-383

HendRIX, W. S. (1924): Some Native Comic Types in the Early Spanish Dram. Ohio

HERnÁNDEZ ARAICO, SUSANA (2004): «El teatro breve de Quevedo y su arte nuevo de hacer ridículos en las tablas: lego-pro-menos a una representación riescénica", en Perinola, 8, pp. 201-234.

Huerta CALVO, JAVIER (1986): "Anatomía de una fiesta teatral burlesca del siglo XVII (Reyes como bufones)", Díez Borque, José María (dir.), Teatro y fiesta en el Barroco, Barcelona, Ediciones del Serbal, pp. 115-136. 


\section{Estado actual de los estudios sobre teatro breve...}

- (1987): «El entremés o la farsa española», en Teatro comico fra Medio Evo e Rinascimento: la farsa, ed. M. Chiabò-F. Doglio, Viterbo, Centro Studi sul Teratro Medioevale e Rinascimentale.

- (1988): «Entremés de El carnaval. Edición y estudio», Dicenda, 7, pp. 357-387.

- (1988): “Poética de los géneros menores», en Géneros menores, pp. 15-31.

- (1995): El nuevo mundo de la risa, Palma de Mallorca, Olañeta.

- (2001): El teatro breve en la Edad de Oro, Madrid, Laberinto.

- (dir.) (2003): Historia del teatro español. Madrid, Gredos, 2 vols.

- y E. PERAL (2000): "Guía bibliográfica del teatro breve», en Gran mundo, pp. 16-17.

JaCK, William S. (1923): The Early Entremés in Spain: The Rise of a Dramtic Form, Philadelphia, University of Pennsylvania.

JAMMES, ROBERT (1978) : "La destruyción de Troya, "entremés» attribué à Góngora", Criticón, 5, pp. 31-52.

KENNEDY, RUTH L. (1972-1973): «Quiteria, comedianta toledana: Her Importance for the Chronology of Quiñones de Benavente and of other Dramatists", en Revista Hispánica Moderna, 37, pp. 1-28.

LÁzARO CARreter, FERNANDO (1974): “El Arte nuevo (vs. 64-73) y el término entremés» [1965], en Estilo barroco y personalidad creadora, Madrid, Cátedra, pp. 187-201.

LINARES, GABRIEL (2003): “Notas para una poética del entremés en el marión de Quevedo", en Texto, espacio y movimiento en el teatro del Siglo de Oro, ed. Aurelio González. México, El Colegio de México, pp. 33-47.

LOBATO, MARÍA LUISA (1989): “Cronología de loas, entremeses y bailes de Agustín Moreto", en Criticón, 46, pp. 125-134.

- (1990): "Versificación del teatro cómico breve de Agustín Moreto", en Homenaje a alberto Navarro González. Teatro del Siglo de Oro, Kassel, Reichenberger, pp. 347-365.

- (1991): «Tres calas en la métrica del teatro breve español del Siglo de Oro: Quiñones de Benavente, Calderón y Moreto", Homenaje a Hans Flasche, Stuttgart, Franz Steiner Verlag, pp. 113-154.

- (1998): “Dos nuevos entremeses para Juan Rana», en Teatro español del Siglo de Oro. Teoría y práctica, Madrid, Iberoamericana-Vervuert, pp. 191-236.

- (1998): «Vejamen de grado en Burgo de Osma (1582). Pleito y entremés inédito de $D$. Pantalón Mondapoços (h. 1578)», en Teatro y poder, pp. 203-224.

- (1999): “Un actor en Palacio: Felipe IV escribe sobre Juan Rana», en Cuadernos de Historia Moderna, 23, pp. 79-111.

- (2001): "Calderón en los sitios de recreación del rey: esplendor y miserias de escribir para palacio", en Calderón: sistema dramático y técnicas escénicas, eds. Felipe B. Pedraza Jiménez, R. González Cañal y E. Marcello, Almagro, Festival de Almagro-Universidad de Castilla La Mancha, pp. 187-224.

- (2000): "Calderón, cisne del Manzanares. Loas cortesanas y conciencia artística", en BHS, 77, pp. 229-262.

- (2000): «Fiesta en Miraflores de la Sierra: La Loa de Nuestra Señora, pieza entremesada atribuida a Calderón", en Calderón, protagonista eminente del teatro europeo, Ed. Kurt y Teo Reichenberger. I, Kassel, Reichenberger, pp. 415-442;

- (2002): “Fiestas teatrales al infante Felipe Próspero (1657-1661) y edición del baile Los Juan Ranas (XI-1658)", en Scriptura, 17, pp. 227-261.

LÓPEZ MENA, SERgio (1994): Escenificaciones neoclásicas y populares (1797-1825), México, Consejo Nacional para la Cultura y las Artes. 
Losada Goya, José MANUEL (1999): Bibliographie critique de la litérature espagnole en France au XVIIe siècle. Genève, Librairie Droz.

Madroñal, ABraham (1995): “Catálogo de entremeses de la Biblioteca de la Real Academia Española", en $B R A E$, 75, pp. 523- 568.

- (1996): "Juan Francés, vida entremesil de un personaje literario", Actas del IV Congreso Internacional de AISO, Alcalá de Henares, Universidad, pp. 963-969.

- (1998a): "Estructuras teatrales de la comedia en el entremés barroco», El Escritor y la Escena, 6, pp. 167-178.

- (1998b): «El alcalde de Mairena, de Fernando de Zárate, un entremés del siglo XVIII rehecho y censurado en el XVIII", en Teatro y poder, pp. 243-252.

- (1998c): "La tierra de Jauja en entremeses barrocos», en América y el teatro español del Siglo de Oro. II Congreso Iberoamericano de Teatro, Cádiz, Universidad, pp. 435-447.

- (1999a): «El entremés en la época de Felipe II y su relación con el entremés barroco». En El teatro en tiempos de Felipe II. Actas de las XXI Jornadas de teatro clásico, ed. Felipe B. Pedraza Jiménez y Rafael González Cañal, Almagro, Universidad de Castilla-La Mancha, Festival de Almagro, pp. 137-162.

- (1999b): «Moralłdad e ideario en los entremeses del XVII: las obras de censura moral», en El escritor y la escena, 7, pp. 149-158.

- (1999c): "Carnaval y entremés en la primera mitad de siglo XVII", en Teatro y carnaval, pp. 73-88.

- (2001): "La burla lingüística en el entremés barroco», en Tiempo de burlas, Madrid, Verbum, pp. 177-197.

- «Teatro breve de autores bilingües: el caso de Pedro Jacinto Morlá», en El Siglo de Oro en el nuevo milenio (en prensa).

- "Tres nuevos manuscritos y una edición desconocida de los entremeses de Calderón", en Homenaje a Stefano Arata, Toulouse, PUM (en prensa).

- y M. Rubio y D. VARELA (1996): «" El Coloquio de las oposiciones, una pieza de teatro jesuítico de carácter cómico ", en Criticón, 68, pp. 31-100.

MANCINI, GUIDO (1955): Gli «entremeses» nell'arte di Quevedo, Pisa, Librería Goliardica Editrice.

MARTÍN FERNÁNDEZ, Ma ISABEL (1999-2001): «La innovación lingüística en Luis Quiñones de Benavente (I)", $A E F, 22$ (1999), pp. 265-286; (II), ibíd, 23 (2000), pp. 307-327; (III) ibíd, 24 (2001), pp. 343-353;

MARTÍNez LóPez, María José (1997): El entremés: radiografía de un género, Toulouse, PUM.

- (1997): «Estudio comparativo de los personajes del teatro breve: del entremés al sainete», en Lenguaje y Textos, Las Palmas-La Coruña, núm. 10, pp. 159-172.

- (2000): "Esta locura que veis': el entremés del siglo XVII", en Gran mundo, pp. 5-8.

- (2002): "La venta y sus representaciones en el teatro áureo", en en Homenaje a Frédéric Serralta. Eds. Françoise Cazal, Christophe González y Marc Vitse. Madrid: Universidad de Navarra-Iberoamicana-Vervuert, pp. 359-380.

Meregalli, F. (1989): "Calderón sainetista ", en El mundo del teatro español en su siglo de Oro: ensayos dedicados a John Varey. Ed. J. M. Ruano de la Haza, Otawa, Dovehouse, 1989 , pp. 351-359.

Merino QUiJANO, GaSPAR (1981): Los bailes dramáticos del siglo XVII, Tesis doctoral. Madrid, Universidad Complutense, 2 vols.

Millé y GIMÉNEZ, JUAN (1930): Sobre la génesis del Quijote, Barcelona, Araluce. 


\section{Estado actual de los estudios sobre teatro breve...}

MÚZquiz Guerreiro, Darlene (1999): «Punishment as Spectacle in Juan Díez de la Fuente's 'Entremés de las moças de la galera'”, en Revista de Estudios Hispánicos, Río Piedras, Puerto Rico, 26, pp. 129-39

Newels, M. (1974): Los géneros dramáticos en las poéticas del Siglo de Oro, London, Tamesis.

Palacios, Emilio (1983): «La descalificación moral del sainete dieciochesco», Teatro menor, pp. 215-233.

PÉREZ LASHERAS, ANTONIO (1988): «El Entremés de los romances y los romances del entremés", en La recepción del texto literario, ed. J-P Étienvre y L. Romero, Zaragoza, Universidad de Zaragoza, pp. 61-76.

Profeti, MARIA GRAZIA (1992): «Condensación y desplazamiento : la comicidad y los géneros menores en el teatro áureo", La vil quimera de este monstruo cómico, Estudios sobre el teatro del Siglo de Oro, Kassel, Reichenberger, pp. 57-69.

Recoules, HenRI (1980): "Motivos entremesiles en el Don Juan de Molière», en BRAE, 60 , pp. $143-163$.

- (1975): «Romancero y entremés», Segismundo, 40, pp. 9-27.

- (1976): «Refranero y entremés», BBMP, 52, pp. 283-293.

ReEd, CoRy A. (1993): The Novelist as Playwright: Cervantes and the 'Entremés nuevo'. New York, Peterlang.

- (1994): “Entremés' and Novel: Comic Theatricality in 'Quijote'», en Miguel de Cervantes. Estudios en la víspera de su centenario, Kassel, Reichenberger, I, p. 197-214.

Reyes PeÑA, Mercedes (1995): “Una fiesta teatral española en la corte de Viena (1667), en En torno al teatro del Siglo de Oro, Almería, Instituto de Estudios Almerienses, pp. 195-231.

RICO, FrANCiSCO (1971): «Para el itinerario de un género menor: algunas loas de la Quinta parte de comedias", Homenaje a William L. Fichter, Madrid, Catalia, pp. 611-621.

RIPODAS ARDANAZ, DAISY (1991): Lo indiano en el teatro menor español de los siglos XVI y XVII, Madrid, Atlas.

RODRÍGUEZ, JosÉ LUIS (2000): «Una colección de entremeses del infante Antonio Pascual de Borbón (1755-1817)", en Palabras para el pueblo, coord. Luis Díaz G. Viana, Madrid, CSIC, pp. 381-401.

RODRÍGUEZ CUADROS, EvANGELINA (1991): "Sobre los entremeses atribuidos a Lope de Vega", en Golden Age Spanish Literature. Studies in Honour of john Varey by his Colleagues and Pupils, London, Westfield College, 1991, pp. 179-189.

- (1983): «Ligaduras y retórica de libertad: la jácara», Teatro menor, pp. 121-136.

- (1997): «El arte calderoniano del entremés», en Pedro Calderón de la Barca. El teatro como representación y fusión de las artes, en Anthropos, Barcelona, Extra 1, pp. 126-131.

- (2000): «La sonrisa de Menipo: el teatro breve de Calderón ante su cuarto centenario", en Estado actual de los estudios calderonianos, ed. de Luciano García Lorenzo, Kassel, Reichenberger-Festival de Almagro, pp. 99-186.

- (2000): «El hato de la risa: identidad y ridículo en el vestuario del teatro breve del Siglo de Oro", en Mercedes de los Reyes (ed.), El vestuario en el teatro español del Siglo de Oro. Cuadernos de Teatro Clásico. Núm. 13-14, Madrid, pp. 109-138.

- (2000b): "La risa del discreto: El teatro cómico breve de Calderón", en Velázquez y Calderón: dos genios de Europa, Madrid, Real Academia de la Historia, pp. 249-282.

- (2001): "Calderón se quita la máscara: teatro cómico breve», en Lecciones calderonianas, coord. por Aurora Egido, Zaragoza, Ibercaja, pp. 105-124. 
- (1998): La técnica del actor español en el Barroco. Hipótesis y documentos, Madrid, Castalia.

- y ANTONIo ToRdera (1983): Calderón y la obra corta dramática del siglo XVII, Londres, Tamesis.

RODRÍGUEZ LÓPEZ-VÁZQUEZ, AlFREDO (2000): “Las Carnestolendas: problemas de atribución y fijación textual", en Calderón, protagonista eminente del teatro europeo, ed. Kurt y Teo Reichenberger, I, Kassel, Reichenberger, pp. 477-500.

RULL, ENRIQUE (1980): «En torno a un entremés anónimo, su posible atribución y otras cuestiones calderonianas", en Segismundo, 27-32, pp. 172-194.

SAla VAlldaURA, Josep MaRia (1994): El sainete en la segunda mitad del siglo XVIII, Lleida, Universidad de Lleida.

- (1999): «Talía juguetona o el teatro de Torres Villarroel», en Rlit, 61, pp. 427-447.

SÁNCHEZ-ImízCOZ, RUTH (1994): El teatro menor en la España del siglo XVII: La contibución de Agustín Moreto, Ann Arbor, UMI.

SCHOlBerg, KenNeTK R. (1954): “Las obras cortas de Calderón», en Clavileño, 25, pp. 13-19.

SENABRE, RICARDO (1979): "Una temprana parodia del Quijote: Don Pascual del Rábano", Homenaje Orozco Díaz, III, Granada, Universidad de Granada, pp. 349-361.

- (1981): “Píramo y Tisbe, entremés inédito de Alonso de Olmedo», AEF, 4, pp. 233-244.

- (1988): «El lenguaje de los géneros menores», Géneros menores, pp. 131-148.

- (1998): “El lenguaje del entremés», en Capítulos de historia de la lengua literaria, Cáceres, pp. 85-122.

SerÉS, Guillermo (1995-1997): “El entremés de los Panza y el 'Tío Abad' de Sanchico ('Quijote' II, 5-72)», en Anales Cervantinos, 33, p. 27-38.

SERrÀ CAMPINS, ANTONI (1987): El teatre burlesc mallorquí, 1701-1850, Barcelona, Curials Edicions Catalanes.

SERRALTA, FRÉDÉRIC (1983): «Antonio de Solís y el teatro menor de Palacio (1650-1660)», Teatro menor, pp. 155-168.

- (1987): «El hidalgo- primera parte- entremés anónimo (¿de Solís?)», en Criticón, 27, pp. 203-225.

- (1990): «Juan Rana homosexual», Criticón, 50, pp. 81-92.

SNELL, A. M. (1994): “El lenguaje de los bailes de Quevedo", en Edad de Oro, 13, pp. 171179.

SOONS, ALAN (1996): «El trasfondo de una obrita festiva: 'El Entremés del Mico'», en RILCE, 12, pp. 99-138.

Solórzano, Carlos (1993): Autos, coloquios y entremeses del siglo XVI, México, Consejo Nacional para la Cultura y las Artes.

STAGG, GEOFFREY (2002): "Don Quijote and the «Entremés de los romances». A Retrospective", en Cervantes. Bulletin of the Cervantes Society of America, 22, pp. 129-150.

Teatro breve $=$ Teatro breve del Siglo de Oro. Criticón, 37 (1987).

Teatro menor = El teatro menor en España a partir del siglo XVI, Madrid, CSIC, 1983.

Teatro y carnaval. Dir. Javier Huerta Calvo. Cuadernos de Teatro Clásico, 12, 1999.

Teatro y poder. VI y VII Jornadas de Teatro Universitario de Burgos, Burgos, Universidad de Burgos, 1998.

TOBAR, $M^{\mathrm{a}}$ LUISA (1983): "Para una protohistoria del entremés : Gil Vicente autor de piezas entremesiles», en Nuovi Annalli della Faculta di Magistero dell' Università di Messina, 1, pp. 661-627.

TORRES NEBRERA, GREGORIO (1979): «Sobre los entremerse contenidos en la Segunda parte de comedias de Tirso de Molina", en AEF, 2, pp. 293-322. 


\section{Estado actual de los estudios sobre teatro breve...}

Tovar, JuAn (ed.) (1988): Teatro selecto. Coloquios y entremeses, de Hernán González de Eslava, México, Secretaría de Educación Pública.

TURner, Elbert D. (1939): Some Aspects of the Dramatic Art of Quiñones de Benavente. Chapel Hill.

URZÁIZ TORTAJADA, HÉCTOR (2002): Catálogo de autores teatrales del siglo XVII, Madrid, Fundación Universitaria Española.

VAlladares Reguero, Aurelio (1998): «Aportación de Pedro Ordóñez de Ceballos al entremés del Siglo de Oro", en RLit, 60, p. 383-402.

VAREY, JOHN E. (1992): “Del entrames al entremés», Teatro y espectáculo en la Edad Media, Alicante, Instituto de Cultura «Juan Gil Albert»-Diputación de Alicante-Ajuntament d'Elx, pp. 65-79.

- y Norman D. Shergold (eds.) (1970): Los celos hacen estrellas, de Juan Vélez de Guevara, Londres, Tamesis.

VÁZQUEZ ESTÉVEZ, ANA (1995): Impresos dramáticos españoles de los siglos XVI y XVII en las bibliotecas de Barcelona, Kassel, Reichenberger, 3 vols.

Vega García-Luengos, GERMÁN (1991): «Teatro e imprenta en Sevilla durante el siglo XVIII: los entremeses sultos", en Archivo Hispalense, 226, pp. 47-98.

- y Rosa Fernández LeRa y ANDRÉS DEL REY SAYAGUÉs (2001): Ediciones de teatro español en la Biblioteca de Menéndez Pelayo (hasta 1833), Kassel, Reichenberger.

VIAN, CESCO (1959): Farse spagnole del secolo d'oro, Milán.

VILCHES DE FRUTOS, Ma FrANCISCA (1985): “Don Quijote y el Entremés de los invencibles hechos de don Quijote de la Mancha de Francisco de Ávila: dos exponentes del paso de la novela al entremés a través de la parodia», en Criticón, 30, pp. 183-200.

VILlaRINo CELA, EDITH MARTA (1998): «Hechizo de amor en un entremés del siglo XVII». En Actas del IV Congreso Internacional de la Asociación Internacional Siglo de Oro (AISO), ed. María Cruz García de Enterría y Alicia Cordón Mesa, Alcalá de Henares, Universidad de Alcalá de Henares, v. II., p. 1655-60.

VITSE, MARC (1988): «Burla e ideología en los entremeses». Géneros menores, pp. 163-176.

Zimic, Stanislav (1992): El teatro de Cervantes, Madrid, Castalia.

Zugasti, Miguel (1999): Edición crítica del teatro cómico breve de Lorenzo de las Llamosas: El astrólogo (sainete) y El bureo (baile)", en Edición y anotación de textos coloniales hispanoamericanos, ed. I. Arellano y J. A. Rodríguez Garrido. Madrid, Universidad de Navarra-Iberoamericana-Vervuert, pp. 399-439.

- (2002): "Poneos ruecas en la cinta»: el trueque espadas-ruecas o el itinerario de un motivo burlesco de la tópica del mundo al revés (con edición de la mojiganga anónima El mundo al revés)", en Pulchre, bene, recte. Estudios en homenaje al prof. Fernando González Ollé, ed. C. Saralegui Platero y M. Casado Velarde, Pamplona, EUNSA, pp. 1443-1477.

\section{Ediciones electrónicas y otros materiales}

- Biblioteca Digital Cervantina (dirigida por Urbina, Eduardo): http://www.csdl.tamu. edu/cervantes/english/ctxt/search/

- Biblioteca virtual Miguel de Cervantes: http:cervantesvirtual.com [Calderón, Quiñones, Cervantes y otros].

- Comedia (Ed. Vern Williamsen): [Quiñones entre otros autores].http://www.coh.arizona.edu/spanish/comedia [Quiñones entre otros autores]. 


\section{Abraham Madroñal}

474

- CORDE: Corpus Diacrónico del Español, de la Real Academia Española: "http:// www.rae.es" [Incorpora buen número de piezas de todos los autores del XVI y XVII mencionados en este trabajo].

- Obras completas de Miguel de Cervantes (ed. Fred Jehle, que sigue la ed. de Schevill y Bonilla): http://users.ipfw.edu/jehle/wcce.htm

- TESO. Teatro Español del Siglo de Oro (ed. M. C. Simón Palmer.): CD. ChadwyckHealey, 1997 [Incluye los entremeses cervantinos y la Jocoseria de Quiñones, además de las partes de Lope y Tirso, que también contienen entremeses]. 